\title{
Strategi Sustainability UMKM Pisang Sale di Kabupaten Bungo dengan Metode SWOT dan Analytic Hierarchy Process (AHP)
}

\author{
Nanik Istianingsih ${ }^{1}$, Emil Salim ${ }^{2}$, Sarjon Defit ${ }^{3}$ \\ Universitas Putra Indonesia YPTK Padang \\ Email : nanikistianingsih66@gmail.com
}

\begin{abstract}
The decline of MSMEs numbers is a challenge for the government to think about how that MSMEs could survive and be sustainable. Determining the sustainability strategy is not necessarily the best strategy and in accordance with the objectives in MSMEs, so that problems arise to determine the best sustainability strategy. Therefore, in this study a combination of the SWOT method and the Analytic Hierarchy Process (AHP) was used to compare the existing alternative sustainability strategies. The difference between this research and previous research lies in determining criteria and sub-criteria and alternative choices. The number of samples used is as many as seven business owners of Banana Sale. For processing research data is assisted by using the Decision Support System (DSS) application. The results of the study on the SWOT analysis show that from the strength of the company it is dominated by products that have distinctive features and competitive prices. In terms of weaknesses, namely small capital and limited product variants are weaknesses that must be addressed immediately. Opportunities include wide market opportunities and loyal consumers. But the threat to this company is limited raw materials, weather and many new competitors to be a concern for the company. From the results of data processing using the Decision Support System application, the highest alternative option is to increase capital so that business continuity can continue.
\end{abstract}

Key word : SWOT, AHP, DSS

Abstrak- Menurunnya jumlah UMKM menjadi sebuah tantangan bagi pemerintah untuk memikirkan bagaimana cara agar UMKM mampu bertahan dan berkelanjutan (sustainability). Penentuan strategi sustainability belum tentu merupakan strategi yang terbaik dan sesuai dengan tujuan yang ada pada UMKM, sehingga muncul permasalahan untuk menentukan strategi sustainability yang paling baik. Oleh karena itu, dalam penelitian ini digunakan penggabungan metode SWOT dan Analytic Hierarchy Process (AHP) untuk membandingkan alternatif strategi sustainability yang ada. Jumlah sampel yang digunakan adalah sebanyak tujuh orang pemilik usaha Pisang Sale. Untuk pengolahan data peniliti dibantu dengan menggunakan aplikasi Decision Support System (DSS). Hasil penelitian pada analisis SWOT diperoleh bahwa dari sisi kekuatan perusahaan ini didominasi oleh produk yang mempunyai cirri khas dan harga yang bersaing. Dari sisi kelemahan yaitu modal yang kecil dan varian produk yang terbatas merupakan kelemahan yang harus segara diatasi. Peluang yang ada diantaranya peluang pasar yang masih luas dan konsumen yang loyal. Namun ancaman bagi perusahaan ini yaitu bahan baku yang terbatas, cuaca dan banyaknya pesaing baru agar menjadi perhatian bagi perusahaan. Dari hasil olah data dengan menggunakan aplikasi Decision Support System di peroleh alternative pilihan yang paling tinggi yaitu Menambah Modal agar keberlangsungan usaha dapat berlanjut.

Key word : SWOT, AHP, DSS 


\section{PENDAHULUAN}

Usaha Mikro, Kecil Dan Menengah (UMKM) dalam perekonomian nasional memiliki peran yang penting dan strategis. Kondisi tersebut dapat dilihat dari berbagai data yang mendukung bahwa eksistensi UMKM cukup dominan dalam perekonomian Indonesia. Setiap unit investasi pada sektor UMKM dapat menciptakan lebih banyak kesempatan kerja. (Bank Indonesia, 2012). Di provinsi Jambi perkembangan UMKM masih mengalami fluktuasi pada pertumbuhannya. Jumlah Usaha Kecil dan Jumlah Tenaga Kerja Terserap cenderung mengalami kenaikan namun hal tersebut tidak terjadi pada Jumlah Usaha Menengah yang mengalami penurunan yang signifikan dan pertumbuhan yang negatif. Fluktuasi pertumbuhan UMKM di Provinsi Jambi dipicu oleh fluktuasi pertumbuhan UMKM di Kabupaten/Kota dalam Provinsi Jambi. Dari jumlah Usaha Menengah di provinsi Jambi yang mampu bertahan di Tahun 2017 sebanyak 555 unit, dari jumlah tersebut jumlah terbanyak pada Tahun 2016 yaitu 380 atau sekitar $68 \%$ diantaranya berada di Kabupaten Bungo dan masih mampu bertahan di Tahun 2017. (Disperindagkop, 2018). Menurunnya jumlah UMKM menjadi sebuah tantangan bagi pemerintah untuk memikirkan bagaimana cara agar UMKM mampu bertahan dan berkelanjutan. Mengingat tingkat persaingan perusahaan semakin ketat, maka untuk mengantisipasi hal tersebut, banyak perusahaan menata ulang strategi persaingannya dengan melakukan kajian terhadap tujuan strategi perusahaan. Dasar yang dijadikan sebagai langkah tersebut adalah kebutuhan pasar, perbandingan dengan perusahaan yang memiliki kinerja terbaik dan juga yang tidak kalah penting melakukan evaluasi yang intens terhadap kompetensi internal maupun eksternal perusahaan itu sendiri. Dengan demikian perusahaan tersebut akan tetap bertahan di ranah persaingan yang makin ketat seperti sekarang ini dan bahkan dapat dengan mudah untuk memperluas usahanya.

Suatu metode untuk menentukan strategi sustainability bagi UMKM adalah dengan mengumpulkan informasi mengenai faktor kekuatan, kelemahan, peluang dan faktor ancaman yang dihadapi UMKM, baik informasi pada masa sekarang maupun dimasa yang akan datang. Penentuan strategi sustainability belum tentu merupakan strategi yang terbaik dan sesuai dengan tujuan yang ada pada UMKM, sehingga muncul permasalahan untuk menentukan strategi sustainability yang paling baik. Oleh karena itu, dalam penelitian ini digunakan penggabungan metode SWOT dan Analytic Hierarchy Process (AHP) untuk membandingkan alternatif strategi sustainability yang ada.

\section{METODOLOGI PENELITIAN}

Analisis SWOT adalah identifikasi berbagai faktor secara sistematis untuk merumuskan strategi perusahaan (Rangkuti, 2009). Analisis ini didasarkan pada logika yang dapat memaksimalkan kekuatan (strengths) dan peluang (opportunities), namun secara bersamaan dapat meminimalkan kelemahan (weaknesses) dan ancaman (threats).

AHP merupakan salah satu metode untuk membantu menyusun suatu prioritas dari berbagai pilihan dengan menggunakan beberapa kriteria (multi criteria). Karena 
sifatnya yang multi kriteria, AHP cukup banyak digunakan dalam penyusunan prioritas. Di samping bersifat multi kriteria, AHP juga didasarkan pada suatu proses yang terstruktur dan logis. (Susila dkk., 2007). Mengambil rata-rata geometrik dari penilaian perorangan merupakan satu cara untuk memecahkan tidak tercapainya consensus atas nilai setelah perdebatan dan pada saat penentuan prioritas tidak semua orang yang menjadi responden dapat hadir. Metode Analytic Hierarchy Process (AHP) adalah suatu alat analisis yang didukung oleh pendekatan matematika sederhana, yang dapat dipergunakan untuk memecahkan permasalahan 'decision making' seperti pengambilan kebijakan atau penyusunan prioritas (Marimin, 2004). Menurut Artika (2013), menyatakan bahwa Analytical Hierarchy Process (AHP) merupakan suatu model pendukung keputusan yang dikembangkan oleh Thomas L. Saaty. Model pendukung keputusan ini akan menguraikan masalah multi faktor atau multi criteria yang kompleks menjadi suatu hirarki, menurut Saaty (1993), hirarki didefinisikan sebagai suatu representasi dari sebuah permasalahan yang kompleks dalam suatu struktur multi level dimana level pertama adalah tujuan, yang diikuti level faktor, kriteria, sub kriteria, dan seterusnya ke bawah hingga level terakhir dari alternatif. Dengan hirarki, suatu masalah yang kompleks dapat diuraikan ke dalam kelompokkelompoknya yang kemudian diatur menjadi suatu bentuk hirarki sehingga permasalahan akan tampak lebih terstruktur dan sistematis. Akhir dari proses AHP adalah prioritas-prioritas dari alternatif-alternatif. Prioritas tersebut dapat digunakan untuk menentukan alternatif terbaik.

Kombinasi faktor SWOT-AHP adalah suatu penggunaan struktur hirarki untuk proses perencanaan strategis berdasarkan studi SWOT, serta adanya penggunaan teknik kuantitatif untuk memperkirakan nilai efisiensi strategi ideal untuk masingmasing strategi yang diusulkan (Osuna, et. al. 2007). Struktur hierarki tersusun atas empat tingkat, yaitu Tingkat pertama, adalah tujuan yang harus dicapai, tingkat kedua adalah terdiri atas empat kelompok faktor teknik SWOT yaitu Kekuatan (S), Kelemahan (W), Peluang (0) dan Ancaman (T), Tingkat ketiga adalah didasari oleh faktor-faktor yang termasuk dalam anggota dari empat kelompok dari tingkat sebelumnya yaitu Kekuatan (S), Kelemahan (W), Peluang (O) dan Ancaman (T) dan tingkat keempat didasari oleh strategi yang harus dievaluasi dan dibandingkan (Osuna, et. al. 2007). Sebuah gambar representasi hierarki disajikan dalam Gambar 1. 




Gambar 1. Representasi Hirarki dari kombinasi SWOT-AHP ( Sumber: Osuna et. al (2007))

Penelitian ini dilakukan dengan pendekatan kuantitatif. Responden yang digunakan berjumlah tujuh orang pemilik usaha Pisang Sale di Kabupaten Bungo.Dalam penelitian ini menitikberatkan proses pengambilan keputusan berdasarkan hasil perhitungan efisiensi strategi global. Disamping itu, dijabarkan bahwa pada penelitian diawali dengan melakukan metode survei/benchmarking ke pelaku usaha (serta pendapat pakar (pemilik usaha). Selanjutnya dilakukan proses wawancara mengenai keberlanjutan suatu usaha dalam mengembangkan usahanya, dan proses identifikasi faktor SWOT untuk evaluasi internal dan eksternal perusahan.. Selain itu, juga adanya sumber literature (Ekotama, 2008) sebagai perbandingan untuk menyusun strategi sustainability bisnis. Dari data identifikasi factor SWOT (evaluasi internal dan eksternal) dan strategi sustainability, digabungkan dalam diagram hierarki penentuan bobot prioritas. Kemudian pembuatan kuesioner AHP untuk analisis AHP dan kuesioner untuk penentuan strategi efisien dari faktor SWOT. Selanjutnya dilakukan penyebaran kuesioner. Kuesioner disebarkan kepada pengambil keputusan yakni pakar/pemilik usaha, salah satu pelaku usaha tersebut. Langkah selanjutnya, pengolahan hasil dengan metode AHP yang diambil bobot prioritas menggunakan geometric mean untuk menentukan relative importance faktor SWOT dan anggota faktor SWOT. Selanjutnya dari hasil relative importance dan hasil kuesioner strategi efisien dilakukan perhitungan nilai evaluasi keseluruhan dari strategi untuk menentukan strategi yang yang menjadi prioritas utama dalam pengembangan bisnis/UMKM.

Dari hasil wawancara diperoleh identifikasi faktor SWOT (evaluasi internal dan eksternal) dan dari hasil kuesioner AHP diperoleh bobot prioritas menggunakan geometric mean untuk menentukan relative importance. Selanjutnya dari hasil kuesioner strategi efisien diperoleh nilai skala dari strategi efisien. Pengolahan penentuan strategi sustainability dengan metode SWOT-AHP menggunakan aplikasi Decision Support System (DSS) . Langkah-langkah analisis adalah sebagai berikut:

1. Metode SWOT

a. Mengidentifikasi faktor SWOT

b. Evaluasi internal dan eksternal SWOT 
2. Penentuan strategi sustainability

3. Penyusunan diagram hierarki bobot prioritas SWOT-AHP

4. Metode AHP
a. Menentukan jenis kriteria yang akan digunakan
b. Menyusun kriteria-kriteria tersebut ke dalam matrik berpasangan.
c. Normalisasi, langkah selanjutnya setelah merumuskan kriteria kedalam matrikdiatas adalah normalisasi.
d. Menentukan Eigen Value.
e. Menghitung nilai lamda $(\lambda)$
f. Menghitung consistency index (CI)
g. Perhitungan konsistensi.
Perhitungan konsistensi ini adalah menghitung penyimpangan dari konsistensi nilai, dari penyimpangan ini disebut Indeks Konsistensi. Perhitungan bobot prioritas diambil dari data jawaban kuisioner responden yang telah dicari dengan perhitungan AHP. Penilaian dilakukan oleh beberapa partisipan yang akan menghasilkan pendapat yang berbeda satu sama lain.

\section{HASIL DAN PEMBAHASAN}

Langkah pertama yang dilakukan dalam penelitian ini adalah membuat skema AHP yang menghubungkan antara Goal, Kriteria, Sub Kriteria dan Alternatif. Skema yang terbentuk dapat dilihat seperti Gambar 2 berikut ini :

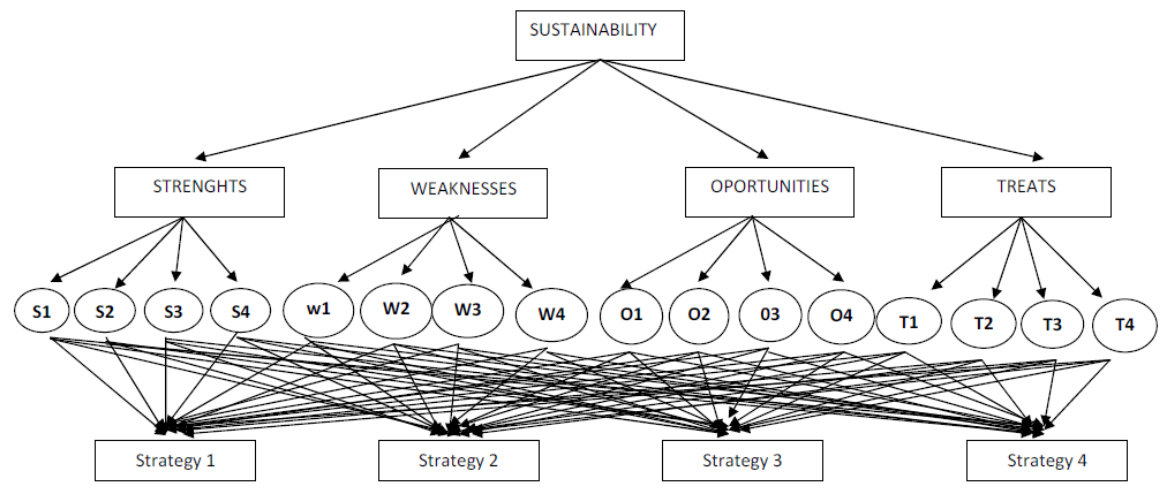

Gambar 2. Skema Hirarki

Dari hasil penyebaran kuesioner terhadap lingkungan internal dan eksternal maka beberapa criteria dalam SWOT dapat dikembangkan berdasarkan indicator kunci yang dapat dirumuskan sebagai berikut:

Tabel 1. Kriteria dan Sub Kriteria (Indikator Kunci)

\begin{tabular}{|l|l|l|l|}
\hline \multicolumn{2}{|c|}{ Lingkungan Internal } & \multicolumn{1}{c|}{ Lingkungan Eksternal } \\
\hline Kriteria & \multicolumn{1}{|c|}{ Indikator } & \multicolumn{1}{c|}{ Kriteria } & \multicolumn{1}{|c|}{ Indikator } \\
\hline 1. Strenghts & S1.Produk berciri khas & 3. Opportunities & 01. Peluang Pasar \\
& S2. Harga Bersaing & & 02. Peluang Promosi \\
& S3. Lokasi Strategis & & 03. Pengembangan \\
\hline
\end{tabular}




\begin{tabular}{|c|l|l|l|}
\hline \multicolumn{2}{|c|}{ Lingkungan Internal } & \multicolumn{1}{c|}{ Lingkungan Eksternal } \\
\hline Kriteria & \multicolumn{1}{|c|}{ Indikator } & \multicolumn{1}{|c|}{ Kriteria } & \multicolumn{1}{|c|}{ Indikator } \\
\hline & S4. Prospek Usaha Baik & & 04. Konsumen Loyal \\
\hline \multirow{2}{*}{ 2. Weaknesses } & W1. Tidak ada Mnj & 4. Treaths & T1. Pesaing baru \\
& W2. Varian Terbatas & & T2. Cuaca \\
& W3. Modal Kecil & & T3. Bahan Baku \\
& W4. Sarana Minim & & T4. Produk Pengganti \\
\hline
\end{tabular}

Selanjutnya penilaian dilakukan terhadap criteria SWOT dengan matrik perbandingan seperti pada Tabel 2 berikut :

Tabel 2. Matrik Perbandingan Berpasangan Kriteria

\begin{tabular}{|l|c|c|c|c|c|}
\hline Kriteria & Strengths & Weaknesses & Opportunities & Treats & Eigen \\
\hline Strengths & 1 & 7 & 5 & 0,50 & 0,40 \\
\hline Weaknesses & 0,14 & 1 & 0,20 & 0,33 & 0,04 \\
\hline Opportunities & 0,20 & 5 & 1 & 7 & 0.33 \\
\hline Treats & 2 & 3 & 0,14 & 1 & 0,23 \\
\hline
\end{tabular}

Sumber : Data diolah, 2019

Dari data diatas dapat dilihat bahwa Kriteria Strengths adalah mendapat prioritas tertinggi dengan nilai eigen 0,40. Langkah berikutnya adalah mencari nilai eigen masing-masing sub criteria berdasarkan indicator kunci. Hasil olah data yang diperoleh dapat dilihat pada table-tabel berikut ini :

Tabel 3. Matrik Perbandingan Berpasangan Kriteria Strengths

\begin{tabular}{|l|c|c|c|c|}
\hline Strenghts & $\begin{array}{c}\text { S1. Produk Berciri } \\
\text { khas }\end{array}$ & $\begin{array}{c}\text { S2. Harga } \\
\text { Bersaing }\end{array}$ & $\begin{array}{c}\text { S3. Lokasi } \\
\text { Strategis }\end{array}$ & $\begin{array}{c}\text { S4. Prospek } \\
\text { Usaha Baik }\end{array}$ \\
\hline $\begin{array}{c}\text { A1. Menjalin } \\
\text { Mitra }\end{array}$ & 0.339 & 0.250 & 0.225 & 0.260 \\
\hline $\begin{array}{c}\text { A2. Menambah } \\
\text { Varian }\end{array}$ & 0.075 & 0.361 & 0.141 & 0.153 \\
\hline $\begin{array}{c}\text { A3. Membuka } \\
\text { Cabang }\end{array}$ & 0.251 & 0.078 & 0.091 & 0.082 \\
\hline $\begin{array}{c}\text { A4. Menambah } \\
\text { Modal }\end{array}$ & 0.334 & 0.302 & 0.542 & 0.503 \\
\hline
\end{tabular}

Sumber : Data Diolah, 2019

Tabel 4. Matrik Perbandingan Berpasangan Kriteria Weaknesses

\begin{tabular}{|l|c|c|c|c|}
\hline \multicolumn{1}{|c|}{ Weaknesses } & $\begin{array}{c}\text { W1.Tidak ada } \\
\text { Manajemen }\end{array}$ & $\begin{array}{c}\text { W2. Varian } \\
\text { Terbatas }\end{array}$ & W3. Modal Kecil & $\begin{array}{c}\text { W4. Sarana } \\
\text { Minim }\end{array}$ \\
\hline $\begin{array}{c}\text { A1. Menjalin } \\
\text { Mitra }\end{array}$ & 0.083 & 0.310 & 0.148 & 0.121 \\
\hline $\begin{array}{c}\text { A2. Menambah } \\
\text { Varian }\end{array}$ & 0.242 & 0.153 & 0.274 & 0.083 \\
\hline A3. Membuka & 0.171 & 0.066 & 0.116 & 0.581 \\
\hline
\end{tabular}




\begin{tabular}{|c|c|c|c|c|}
\hline Weaknesses & $\begin{array}{c}\text { W1.Tidak ada } \\
\text { Manajemen }\end{array}$ & $\begin{array}{c}\text { W2. Varian } \\
\text { Terbatas }\end{array}$ & W3. Modal Kecil & $\begin{array}{c}\text { W4. Sarana } \\
\text { Minim }\end{array}$ \\
\hline $\begin{array}{c}\text { Strategy } \\
\text { Cabang } \\
\text { Menambah }\end{array}$ & 0.501 & 0.469 & 0.460 & 0.213 \\
\hline
\end{tabular}

Sumber : Data Diolah, 2019

Tabel 5. Matrik Perbandingan Berpasangan Kriteria Opportunities

\begin{tabular}{|l|c|c|c|c|}
\hline Opportunities & $\begin{array}{c}\text { 01. Peluang } \\
\text { Pasar }\end{array}$ & $\begin{array}{c}\text { 02. Peluang } \\
\text { Promosi }\end{array}$ & $\begin{array}{c}\text { 03. Pengembangan } \\
\text { Produk }\end{array}$ & $\begin{array}{c}\text { 04. Konsumen } \\
\text { Loyal }\end{array}$ \\
\hline $\begin{array}{c}\text { A1. Menjalin } \\
\text { Mitra }\end{array}$ & 0.314 & 0.351 & 0.202 & 0.433 \\
\hline $\begin{array}{c}\text { A2. Menambah } \\
\text { Varian }\end{array}$ & 0.158 & 0.154 & 0.340 & 0.212 \\
\hline $\begin{array}{c}\text { A3. Membuka } \\
\text { Cabang }\end{array}$ & 0.104 & 0.116 & 0.148 & 0.083 \\
\hline $\begin{array}{c}\text { A4. Menambah } \\
\text { Modal }\end{array}$ & 0.442 & 0.377 & 0.304 & 0.270 \\
\hline
\end{tabular}

Sumber : Data Diolah, 2019

Tabel 6. Matrik Perbandingan Berpasangan Kriteria Treats

\begin{tabular}{|l|c|c|c|c|}
\hline Treats & T1. Pesaing Baru & T2. Cuaca & T3. Bahan Baku & $\begin{array}{c}\text { T4. Produk } \\
\text { Pengganti }\end{array}$ \\
\hline $\begin{array}{c}\text { Atrategy } \\
\text { Mitra }\end{array}$ & 0.356 & 0.176 & 0.350 & 0.328 \\
\hline $\begin{array}{c}\text { A2. Menambah } \\
\text { Varian }\end{array}$ & 0.207 & 0.358 & 0.188 & 0.187 \\
\hline $\begin{array}{c}\text { A3. Membuka } \\
\text { Cabang }\end{array}$ & 0.067 & 0.077 & 0.098 & 0.072 \\
\hline $\begin{array}{c}\text { A4. Menambah } \\
\text { Modal }\end{array}$ & 0.369 & 0.386 & 0.362 & 0.411 \\
\hline
\end{tabular}

Sumber: Data Diolah, 2019

Pada tahap penghitungan akhir terhadap Alternatif Strategi yang akan dipilih diperoleh hasil sebagai berikut:

Tabel 7. Pilihan Alternatif Strategi

\begin{tabular}{|l|c|c|}
\hline \multicolumn{1}{|c|}{ Alternatif Strategi } & Nilai Akhir & Peringkat \\
\hline A1. Menjalin Mitra & 0.263 & 2 \\
\hline A2. Menambah Varian & 0.231 & 3 \\
\hline A3. Membuka Cabang & 0.108 & 4 \\
\hline A4. Menambah Modal & 0.396 & 1 \\
\hline
\end{tabular}

Sumber : Data Diolah, 2019 
Dari hasil olahan data diatas bahwa sustainability sebuah perusahaan dalam hal ini adalah Usaha Mikro Kecil dan Menengah sangat ditentukan oleh Kekuatan (Strenghts) yang dimiiki oleh perusahaan itu sendiri. Kekuatan itu dapat dibangun dengan menciptakan produk yang mempunyai ciri khas tersendiri sehingga berbeda dengan produk serupa dari daerah lain. Kekuatan berikutnya yang dapat dipertahankan adalah menjaga harga sehingga mampu bersaing dengan harga produk sejenis. Perusahaan bisa menciptakan varian produk sesuai dengan segmentasi pasar selama harganya masih terjangkau oleh konsumen. Letak perusahaan yang berlokasi didaerah sentra oleh-oleh juga merupakan kekuatan yang baik apalagi jika perusahaan mempunyai mitra untuk pengembangan produk atau pemasaran.

Dari sisi Kelemahan (Weaknesses) perusahaan masih didominasi dengan kurangnya Modal dan varian produk yang terbatas. Hal ini disebabkan karena perusahaan dikelola dengan manajemen tradisional dan sarana yang minim.

Namun demikian masih ada Peluang (Opportunities) bagi perusahaan dengan masih terbukanya peluang pasar yang luas dan konsumen yang loyal terhadap produk yang diciptakan. Dari sisi Ancaman (Treats), perusahaan ini masih sangat rentan dengan bahan baku yang terbatas dan masih bergantungnya produksi pada cuaca. Sehingga apabila terjadi gangguan pada bahan baku dan cuaca maka perusahaan akan menemui kendala dalam produksi. Selain itu munculnya pesaing barudan adanya produk pengganti dapat mempengaruhi perusahaan.

Pada tahap terakhir yaitu Pemilihan Keputusan terhadap strategi yang akan dipilih untuk menjaga sustainability UMKM, maka peringkat tertinggi untuk dipilih adalah Strategi ke 4 yaitu Menambah Modal. Hal ini disebabkan karena UMKM sangat bergantung pada modal yang mereka miliki. Karena perusahaan ini dikelola sacara tradisional terkadang mereka tidak menggunakan system pembukuan yang baik yang memisahkan antara modal dan pendapatan sehingga modal usaha yang selayaknya digunakan untuk produksi tetapi dipakai untuk konsumsi rumah tangga. Modal awal untuk perusahaan memang tergolong kecil yaitu Rp. 20.000.000,- sampai Rp. 30.000.000,- sehingga sudah sepantasnya perusahaan untuk menambah modal usaha yang dapat bersumber dari pemerintah ataupun dari mitra. Dengan menambah modal usaha merupakan pilihan alternative terbaik untuk kelangsungan perusahaan.

\section{KESIMPULAN}

a. Bahwa sustainability UMKM dapat dibangun dibangun dengan melihat lingkungan internal dan eksternal perusahaan. Dari sisi kekuatan perusahaan ini didominasi oleh produk yang mempunyai ciri khas dan harga yang bersaing. Dari sisi kelemahan yaitu modal yang kecil dan varian produk yang terbatas merupakan kelemahan yang harus segara diatasi. Peluang yang ada diantaranya peluang pasar yang masih luas dan konsumen yang loyal. Namun ancaman bagi perusahaan ini yaitu bahan baku yang terbatas, cuaca dan banyaknya pesaing baru agar menjadi perhatian bagi perusahaan.

b. Dari hasil olah data dengan menggunakan aplikasi Decision Support System di peroleh alternative pilihan yang paling tinggi yaitu Menambah Modal agar keberlangsungan usaha dapat berlanjut. 
c. Penelitian ini masih banyak kekurangan sehingga diharapkan Bagi peneliti yang akan datang agar dapat melakukan penelitian dengan menambah indicatorindikator kunci dengan indicator lain sehingga penelitian ini akan semakin berkembang dan pilihan alternative semakin baik.

d. Bagi perusahaan agar dapat mencari sumber sumber keuangan yang nantinya akan mampu menambah modal usaha. Selain itu manajemen perusahaan perlu diperbaiki dan perusahaan jugadapat mencari sumber-sumber bahan baku yang yang baru. Dan bagi pemerintah agar dapat membina UMKM dan menambah jumlah bantuan dan kucuran modal bagi UMKM.

\section{Daftar Pustaka}

[1] E. E. Osuna and A. Aranda, "Combining SWOT and AHP Techniques For Strategic Planning," J. Manag. Bus., pp. 12-25, 2007.

[2] F. Rangkuti, Teknik Membedah Kasus Bisnis Analisis SWOT Cara Perhitungan Bobot, Rating, dan OCAI. 2013.

[3] R. Artika, "Penerapan Analitycal Hierarchy Proccces(AHP) Dalam Pendukung Keputusan Penilaian Kinerja Guru Pada SD Negeri 095224," Jurnla Pelita Inform. Budi Darma, vol. 4, no. 3, pp. 123-128, 2013.

[4] S. Ekotama, No Title. Yogyakarta: Media Pressindo, 2008.

[5] Thomas L. Saaty, "Decision making with the analytic hierarchy process," Int. J. Servces Sci., vol. 1, no. 1, p. 83, 2018.

[6] W. Jambi, "Provinsi jambi," Peraturan. Walikota Jambi Nomor 18 Tahun 2016, 2016.

[7] W. R. Susila; and E. Munadi, "Penggunaan Analytical Hierarchy Process Untuk Penyusunan Prioritas Proposal," Inform. Pertan., vol. 16, no. 2, pp. 983-998, 2007. 